\title{
Use of macroinvertebrate assemblage to assess the ecological integrity of Nyando Wetlands, Kenya
}

\author{
Patrick Oduor Orwa ${ }^{1 \star}$, Phillip Okoth Raburu ${ }^{1}$, Julius Kipkemboi ${ }^{2}$, Priscah Rongoei ${ }^{2}$, Okeyo- \\ Owuor J. B. ${ }^{3}$ and Steve Omari ${ }^{1}$ \\ ${ }^{1}$ Department of Fisheries and Aquatic Sciences, University of Eldoret, P.O. Box 1125, Eldoret, Kenya. \\ ${ }^{2}$ Department of Biological Sciences, Egerton University, Kenya. \\ ${ }^{3}$ VIRED International, Kisumu, Kenya.
}

Accepted May 27, 2013

\begin{abstract}
This study aimed to investigate changes in macroinvertebrate assemblage within Nyando wetlands and developed an index of biotic integrity for monitoring human disturbances. Triplicate macroinvertebrate samples were collected monthly for seven months using a scoop net. They were sorted live, counted and identified to genus level. Water samples for nutrients were collected and analyzed using standard methods. Physico-chemical parameters were taken in situ using electronic meters. Macroinvertebrates were analyzed for richness, diversity, dominance and abundance. Abundance was correlated with physico-chemical parameters. Kruskal-Wallis test was used to test spatial differences in macroinvertebrate community. Metrics for index of biotic integrity were chosen, tested, and a 5, 3, 1 scoring criteria was used. A total of $\mathbf{4 5}$ genera were identified and Kruskal-Wallis test analysis revealed significant spatial differences in macroinvertebrate abundance. Repeated measures ANOVA showed significant spatio-temporal differences. Tolerant macroinvertebrates were abundant at the disturbed sites whereas intolerant taxa showed a strong negative correlation with nutrient levels. Sites with higher disturbance recorded a total index score far below the reference site score. The results indicated that macroinvertebrates in Nyando wetlands can be used to monitor its ecological integrity. The IBI developed should be used to protect the lake from eutrophication.
\end{abstract}

Key words: Human disturbance, water quality, index of biotic integrity.

\section{INTRODUCTION}

In Kenya, land use changes on various catchments and water towers have been increasingly characterized by human settlement, deforestation, wetland reclamation and unsustainable agricultural activities (UNEP, 2006; GEF, 2007; Aura et al., 2010). In Lake Victoria basin, increased deforestation (FAO, 2005) and unsustainable agriculture coupled with agro-industrial activities and rapid urbanization pose threats to the wellbeing of aquatic ecosystems (Raburu et al., 2009). The Nyando River which partly originates from the Mau complex is very significant in providing water for domestic and industrial use and is also home for biodioversity. However, deforestation activities coupled with unsustainable agricultural activities pose a challenge to the conservation and realization of the wetland services (GEF, 2007). River Nyando (Figure 1) drains a catchment characterized by diverse land use types including forestry, large-scale and small-scale agriculture, urban centers and agro-based industries.

Given that community livelihoods in the lower 


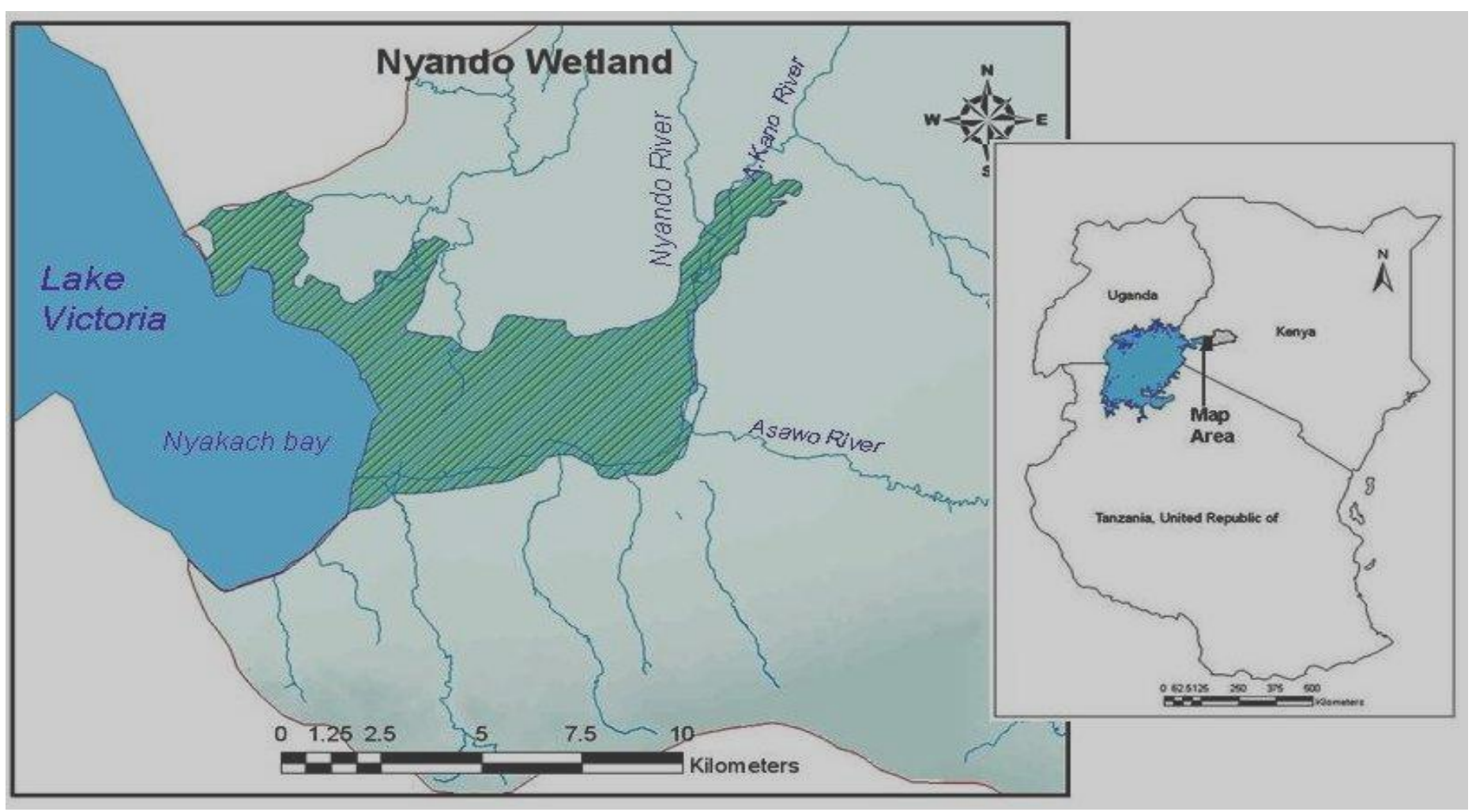

Figure 1. Map showing Nyando wetland and its draining rivers.

reaches of the River Nyando Basin revolve around agricultural crop production and fisheries, it is imperative that the wetland ecosystem is closely monitored and conserved to ensure sustainability. As agricultural intensification is likely to increase to cope with the increasing human population in the study area, the nutrient levels in the wetland and food sources for macroinvertebrate communities are likely to be affected. These changes will be reflected in the composition and distribution of functional feeding groups (FFGs) along the wetland. High nutrient levels in the wetland can eventually find their way into Lake Victoria which is already experiencing eutrophication.

A cost effective monitoring tool is therefore needed to allow regular assessment of the wetland ecological integrity. This can only be achieved through establishment of a biomonitoring protocol unique to the area. By assessing the distribution of macroinvertebrate assemblages as they occur within the wetland, the level of perturbation of the wetland can be determined. Macroinvertebrates have proved to be reliable indicators of environmental integrity, are diverse, and can be easily identified (Griffith et al., 2005).

The overall objective of the study was to assess the spatial and temporal variation of macro-invertebrate assemblage in Nyando wetlands and derive an index for monitoring changes in the ecological integrity of the wetland ecosystem within Lake Victoria basin.

\section{MATERIALS AND METHODS}

\section{Study area}

Nyando wetland which is dominated by Cyperus papyrus L. is located in the western region portion of Lake Victoria in Kenya (Figure 1) and covers an area of about 5,000 ha (G.O.K, 1996). It lies between longitude $34^{\circ} 13^{\prime \prime}$ and $34^{\circ} 52^{\prime}$ East and latitude $0^{\circ}$ $4^{\prime}$ 'and $0^{\circ} 32^{\prime}$ South of Equator. The wetland receives a mean annual rainfall of $1138 \mathrm{~mm}$ with the highest levels during the months of March, April, May and June, and low levels during the months of December and January. The swamp has a poorly drained deep clay soils and is characterized by several economic activities. The main crops under cultivation in this wetland include sugar cane, rice, maize and vegetables though in a small-scale. Other activities in the wetland are cattle grazing, domestic washing, macrophyte harvesting and fishing.

\section{Sampling stations}

To capture the effects of different human activities on water quality, sites were selected along the wetland. The sampling stations were marked from three study transects, Ogenya (OG) transect (E34 ${ }^{\circ}$ 51'; S00 $\left.{ }^{\circ} 16^{\prime}\right)$, Singida (S) transect (E34 ${ }^{\circ}$ 53'; S00 $\left.{ }^{\circ} 16^{\prime}\right)$, and Wasare (W) transect (E034 ${ }^{\circ} 5^{\prime}$; S00 $\left.{ }^{\circ} 16^{\prime}\right)$ as shown in Figure 2. Singida transect was in a permanently flooded area, Wasare transect was in a seasonally flooded area, while Ogenya transect was in an area that experience both lake and riverine influence

Station S1 (E340 53.059'; S000 16.841') was located in a relatively undisturbed macrophyte covered location in Singida transect, station S2 (E34 ${ }^{\circ} 53.039^{\prime}$; S00 $\left.{ }^{\circ} 16.836^{\prime}\right)$ was in an area characterized by fishing (setting of traps), and little signs of cattle 


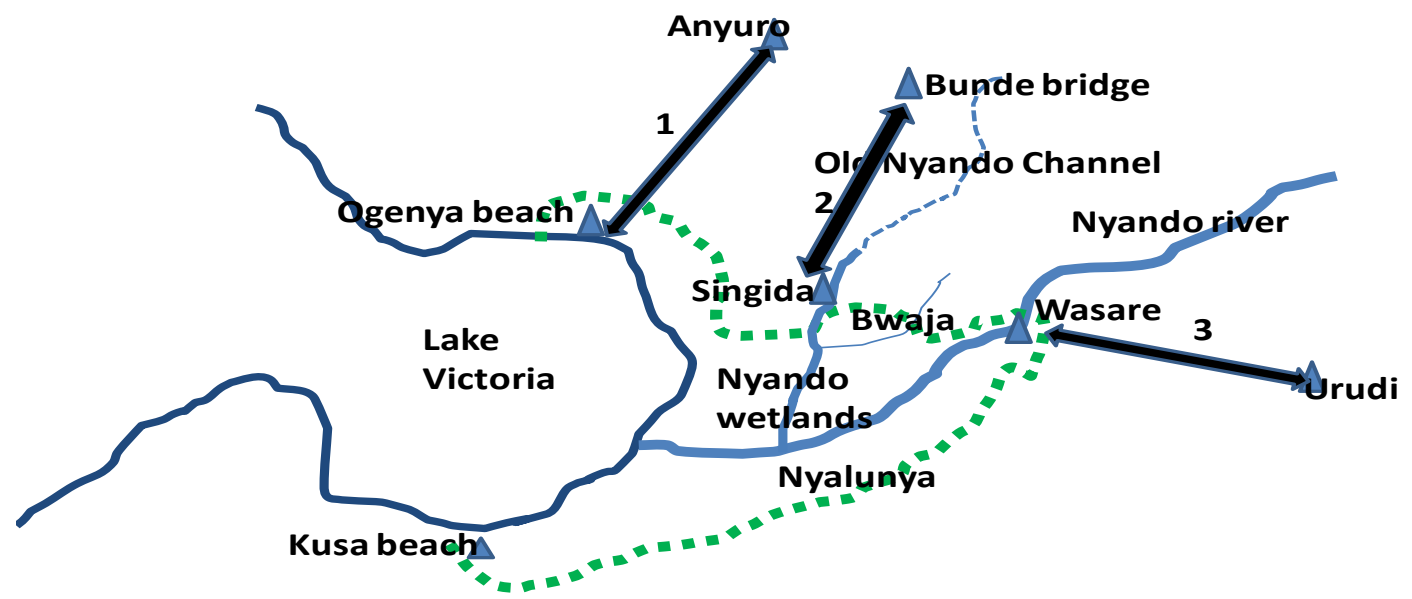

Figure 2. Directions to the sampling transects. Arrows show direction from the road to a study transect while numbers 1,2 and 3 indicates transect.

grazing and macrophyte harvesting while S3 (E34 ${ }^{\circ} 53.015^{\prime} \mathrm{S}^{\circ} 0^{\circ}$ 16.821') was located at the beach in Singida transect an area characterized by, agricultural farms (sugar cane, horticulture and maize), and fishing activities (fish landing and washing of fish stomach contents).

Station OG1 (E34 $51.134^{\prime}$; S00 $\left.{ }^{\circ} 16.161^{\prime}\right)$ was located at the thickly macrophyte covered site in Ogenya transect characterized by fishing activities and macrophyte harvesting. Station OG2 (E34 51.141'; S00 $\left.{ }^{\circ} 16.147^{\prime}\right)$ was in an area characterized by, fishing, macrophyte harvesting and cattle grazing, while OG3 (E34 ${ }^{\circ}$ $51.241^{\prime} ; \mathrm{S} 00^{\circ} 16.165^{\prime}$ ) was located at the beach, a place disturbed by fishing activities, grazing, agriculture (sugar cane, horticulture, and maize) and domestic washing.

Station W1 (E 034 ${ }^{\circ} 55.101^{\prime}$; S $\left.00^{\circ} 16.349^{\prime}\right)$, was in an area thickly vegetated and characterized by some fishing activities like setting of fish traps and macrophyte harvesting in Wasare, while W2 (S $00^{\circ} 16.441^{\prime}, \mathrm{E} 034^{\circ} 55.115^{\prime}$ ) was in an area that experienced human activities like grazing and fishing in Wasare transect; station R/F was a site at the rice fields.

\section{Sampling}

Data on physico-chemical parameters, and macroinvertebrate assemblages were collected monthly for a period of seven months, beginning from October 2010 to April 2011. This period covered part the wet season (October, March and April) and part of the dry season (from November 2010 to February 2011).

\section{Macroinvertebrate sampling}

In each sampling station, three replicate macroinvertebrate samples were collected using a scoop net $\left(0.5 \mathrm{~m}^{2}, 500 \mu \mathrm{m}\right.$ mesh size). The macroinvertebrates were washed through a $300 \mu \mathrm{m}$ mesh size sieve, hand sorted and preserved in $70 \%$ alcohol in labeled vials. In the laboratory, the macroinvertebrates were identified to genus level according to Merritt and Cummins (1996) and Quigley (1977), and then counted. Taxon diversity, richness, evenness and relative abundance were done to determine macroinvertebrate composition in all stations along Nyando wetlands.

The macroinvertebrates identified were further categorized into their functional feeding groups according to Merrit and Cummins (1996).

\section{Physico-chemical parameters and nutrients}

The physico-chemical parameters were measured in situ at all sampling stations before mid day at each sampling occasion. The parameters measured at each site included temperature, dissolved oxygen (DO), electrical conductivity and $\mathrm{pH}$. Dissolved oxygen was measured using OXi 3210 (WTW Wissenschaftlich-Technische), $\mathrm{pH}$ was measured using $\mathrm{pH} 3210$ (Weilheim), and conductivity was measured using COND 3210 (Werkstitten $\mathrm{GmbH}$ ) meters prior to macroinvertebrate sampling. The water quality parameter values were then summarized as a range between the minimum and the maximum value for each parameter at each station.

Water samples for total phosphorus and total nitrogen were collected in triplicates during each sampling occasion using $250 \mathrm{ml}$ bottles, fixed at the site of collection using $1 \mathrm{ml}$ concentrated sulphuric acid and then transported to the laboratory where they were analyzed according to standard methods (APHA, 1998). Total nitrogen was determined using the Kjeldahl method (APHA, 1998) while total phosphorus was measured using the Persulfate digestion method (APHA, 1998).

\section{M-IBI Development}

\section{Reference site}

Reference site refers to a site of low relative disturbance or pristine, but a pristine site is however hard to find currently (Mason, 2002). For the purpose of this study, a site was considered as reference if the site was in an area of high macrophyte density, and no detectable effects of grazing or human activity (Robert and Rankin, 1998) within which in this case, was station S1 along Singida transect. Impaired sites were identified as those converted and damaged sites associated with livestock grazing, fishing activities, domestic washing, row crop agriculture and macrophyte harvesting. Sites that did not belong to the two categories were considered to belong to the moderate range of conditions.

\section{Metric selection and testing}

In this study, various metrics were selected that acted as indicator attributes in assessing the status of macroinvertebrate assemblages in response to perturbation in the study area (Table 
Table 1. Metrics for macroinvertebrates that were considered for development of an index of biotic integrity and the predicted responses to pollution.

\begin{tabular}{|c|c|c|}
\hline Metric & Metric Definition & Predicted response \\
\hline Simpson richness index & Value of Simpson richness index & Decrease \\
\hline Number of Ephemeroptera genera & Total number of Mayfly genera & Decrease \\
\hline Number of Trichoptera genera & Total number of caddisfly genera & Decrease \\
\hline $\begin{array}{l}\text { Number of Ephemeroptera-Plecoptera- } \\
\text { Trichoptera genera }\end{array}$ & Total number of taxa from mayfly, stonefly and caddisfly & Decrease \\
\hline Percent non-insect individuals & $\begin{array}{l}\text { Percentage of individuals no belonging to the insect } \\
\text { orders }\end{array}$ & Increase \\
\hline Percentage Diptera individuals & Percentage of midge individuals & Increase \\
\hline EPT: Diptera individuals ratio & $\begin{array}{l}\text { Ratio of individuals belonging to mayfly, stonefly and } \\
\text { caddisfly orders to that of midges }\end{array}$ & Decrease \\
\hline Percent dominant 2 or 3 genera & Percentage of individuals in 2 or 3 most dominant genera & Decrease \\
\hline Percent intolerant individuals & Percentage of individuals in pollution sensitive genera & Decrease \\
\hline Percent tolerant individuals & Percentage of individuals in pollution tolerant genera & Increase \\
\hline Percent filterer individuals & Filter fine organic material & Increase \\
\hline Percent scraper individuals & Feed on algae at the bottom & Decrease \\
\hline Percent predator individuals & Carnivores- scavengers, engulf or pierce prey & Decrease \\
\hline Percent gatherer individuals & Collect fine deposited organic material & Increase \\
\hline
\end{tabular}

Source: Raburu et al. (2009).

Table 2. Integrity classes for final IBI development.

\begin{tabular}{lc}
\hline Class of integrity & Ranges for IBI \\
\hline Excellent & $>45$ \\
Good & $36-45$ \\
Fair & $26-35$ \\
Poor & $16-25$ \\
Very poor & $<16$ \\
\hline
\end{tabular}

1). Composition attributes like relative abundance and diversity were used to provide information on the structure of the assemblage (Roy et al., 2001).

\section{Scoring}

The 1, 3, 5 scoring system as used in developing macroinvertebrate IBIs (Karr and Chu, 1981; Kerans and Karr, 1994; Barbour et al., 1999; Aura et al., 2010) was used. For metrics that decrease with degradation and high nutrient levels, a score of 5 was made for sites when the values were above the $75^{\text {th }}$ percentile of reference site values; a score of 3 was given when the value was between the 75th percentile of reference and the 50th percentile values; and a score of 1 when the value was below 50th percentile of the reference site values. For metrics that increased with impairment, a score of 5 was made when the value of the metric was below the 50th percentile of impaired site values; 3 when the value was between the 75th percentiles of impaired and the 50th percentile values; and 1 when the value was above 75th percentile of impaired site values. The scored metrics were then summed to obtain the final $\mathrm{M}-\mathrm{IBI}$ score. Five integrity classes (Table 2) were defined using total M-IBI scores.

\section{Data analysis}

Data storage and management was done using Microsoft Excel spreadsheet for Windows 2007 while analysis was done using Minitab ${ }^{\mathrm{TM}}$ Version 14.0 for Windows. The values for ShannonWiener diversity index, mean abundance and the Simpson taxon richness index were summarized for the study period as mean \pm SE values for each sampling station. Total number of genera, percentage EPT, percentage diptera, percentage oligochaetes and the relative abundance was also calculated for each station.

Spatial and temporal variation in macroinvertebrate abundance was tested using Kruakal-Wallis test while variation in physicochemical parameters was tested using repeated measures ANOVA at $95 \%$ confidence limits. Duncan's multiple range test (DMRT) was then performed post hoc to identify the specific stations that differed from one another. Physico-chemical parameters and nutrient levels were correlated with macroinvertebrate abundance using Spearman's correlation analysis. Macroinvertebrate metrics were tested using Mann-Whitney $U$ test to eliminate the macro invertebrate metrics that did not show significant differences at $95 \%$ confidence limits. The macroinvertebrates were also correlated with 
disturbance gradients which included acidity $(\mathrm{pH})$, conductivity, nutrients (nitrogen and phosphorus) and decomposition (DO) to determine whether there were relationships.

\section{RESULTS}

\section{Macroinvertebrate diversity and abundance}

During the study, 3508 macroinvertebrates from 44 genera belonging to 11 orders and 38 families were identified (Table 3 ). The main taxonomic groups sampled were Hemiptera, Ephemeroptera, Coleoptera,

Oligochaeta, Plecoptera, Diptera, Pulmonata and Prosobranchiata. Other groups sampled in small numbers include Trichoptera, Odonata, and Isopoda. The order Hemiptera had the highest number of genera $(\mathrm{n}=$ 10) out of the 44 genera sampled and highest relative abundance with $24.5 \%$ of the total abundance, followed by Ephemeroptera and Coleoptera at 16.2 and 15.4\%, respectively (Figure 3 ). The order Trichoptera had the lowest relative abundance (1.8\%). Gerris $\mathrm{sp}$. was dominant in the wetland with a relative abundance of $3.81 \%$ followed by Cleon sp. (3.79\%) while Tinodos sp. had the lowest relative abundance $(0.57 \%)$ (Table 3 ).

\section{Spatial and temporal variation}

Three genera, Cleon sp., Gyrinus sp. and Gerris sp. were sampled at all stations (Table 3), while Tubifex sp. was only found at one sampling station. Lumbricus sp., Erpobdella sp. and Vellia sp. were found in only two stations. Tinodos sp., Hydroptilla sp. and Hydropsche sp. though found in more than two sites had the lowest relative abundance. Trichoptera, which is a sensitive taxa was only encountered at stations $\mathrm{S} 1, \mathrm{~W} 1$ and $\mathrm{OG} 1$ (Table 3) and was missing in all sites from December 2010. Plecoptera which is also sensitive taxa was not sampled at the disturbed stations S3, R/F and OG3.

In terms of taxon diversity (Table 4), Singida transect had a total of 35 genera, Wasare transect had 32 genera and Ogenya transect had 28 genera. The diversity index was similarly highest in Singida transect $(2.11 \pm 0.03)$, followed by Wasare transect $(2.02 \pm 0.17)$, while Ogenya transect had a diversity index of $1.91 \pm 0.04$.

The total abundance varied between the study transects with Singida transect having the highest total abundance of 1,456 macroinvertebrates, Wasare transect had a total abundance of 1,058 macroinvertebrates while Ogenya transect had the lowest total abundance of 1,091 macroinvertebrates. Station $\mathrm{S} 1$ had the highest number of genera (35) followed by W1 (32) while S3, R/F and OG3 had the lowest number of genera, that is, 15, 18 and 15 , respectively (Table 4).

In all the sampling transects, macroinvertebrate mean abundance decreased as sampling moved towards the dry land (S1-S3, OG1-OG3 and W1-R/F) where there was increased human activity (Figure 4). Station S1 had the highest abundance followed by $\mathrm{S} 2$ where as station OG3 had the lowest macroinvertebrate abundance (Figure 4)

The most abundant taxa in station S1 were of order Coleoptera that formed $26.1 \%$ of total abundance in the station, while the least was Trichoptera having $0.8 \%$ of the total. In station S2, Hemiptera was the most abundant order representing $31.4 \%$ of total abundance followed by Ephemeroptera (23.1\%). Station W1 was dominated by Hemipterans covering 25.1\%. Ephemeroptera, Hemiptera, Coleoptera and Diptera accounted for more than $71 \%$ of total number of individuals collected during the entire study period. Cleon sp. and Gerris sp. dominated the samples in station S1 with 19.8 and $19.1 \%$ followed by Mesovelia sp. (12.6\%), Gyrinus sp. (11.6\%), Caenis sp. (11.3\%), Chloroperla sp. (8.5\%) and Planorbis (4.3\%) with the rest covering the remaining $12.8 \%$. A slightly similar trend was observed in station $\mathrm{W} 1$ during the months of October and November. In station S3 Chironomus sp. $(28.6 \%)$ dominated the samples followed by Belostoma sp. (21.6\%), Erpobdella sp. (10.8\%), Gerris sp. $(9.1 \%)$, among others. The trend was the same for station OG3. Station R/F experienced a high relative mean abundance of Notonecta sp. (27.42 \pm 0.51$)$ followed by Tabanus sp. and Chironomus sp. (13 0.29 and $11 \pm 0.31$, respectively). Station $\mathrm{S} 2$ and $\mathrm{OG} 2$ were dominated by Gerris sp. and (Cleon sp.).

The abundance of macroinvertebrates reduced over time except for the dipterans, oligochaetes, and the prosobranchiata that slightly increased in abundance as time moved from October to end of February. The mean abundance for each site reduced with time from November 2010 to February 2011 then there was an increase during the months of March and April 2011. Wasare transect recorded a large difference in taxa number from 32 genera during the wet months of October and November which dropped to 13 in January. The relative abundance of tolerant taxa were highest at the more disturbed stations of S3 (48\%) and OG3 at $49.2 \%$ (Table 4). Kruskal-wallis test revealed significant variation in macroinvertebrate abundance between sampling stations $(H=44.65, p=0.000$ and sampling occasions $(H$ $=51.02, p=0.001$ )

The values of different community attributes are shown in Table 4. Diversity index were highest in station S1 $(2.47 \pm 0.05)$, followed by W1 $(2.37 \pm 0.13)$, while S3 had the lowest diversity index of $1.49 \pm 0.02$.

\section{Nutrients}

The nutrient concentrations recorded along Nyando wetlands showed variations between sampling months (Figure 5). The levels were highest during the month of February $(\mathrm{TP}=0.353 \pm 0.13 \mathrm{mg} / \mathrm{L} ; \mathrm{TN}=0.129 \pm 0.07$ $\mathrm{mg} / \mathrm{L}$ ), while it was lowest during the rainy months (Figure 6) of October, November and March were lower than the dry seasons which could be due to dilution effect. 
Table 3. List of macroinvertebrate taxa found in Nyando wetlands during the study period ( $x$ shows presence of macroinvertebrate at a station).

\begin{tabular}{|c|c|c|c|c|c|c|c|c|c|c|c|}
\hline Order & Family & Genus & S1 & S2 & S3 & $R / F$ & W1 & W2 & OG1 & OG2 & OG3 \\
\hline \multirow{6}{*}{ Ephemeroptera } & \multirow{2}{*}{ Baetidae } & Cleon sp. & $x$ & $x$ & $x$ & $x$ & $x$ & $x$ & $x$ & $x$ & $x$ \\
\hline & & Baetis sp. & $x$ & & & $x$ & $x$ & $x$ & $x$ & $x$ & \\
\hline & \multirow{2}{*}{ Ephemerelidae } & Ephemerella sp. & $x$ & $x$ & & & $x$ & $x$ & $x$ & $x$ & \\
\hline & & Hydrophlebia sp. & & & & & $x$ & & & & \\
\hline & Caenidae & Caenis sp. & $x$ & $x$ & & & $x$ & $x$ & $x$ & $x$ & \\
\hline & Gerridae & Gerris sp. & $x$ & $x$ & $x$ & $x$ & $x$ & $x$ & $x$ & $x$ & $x$ \\
\hline \multirow{8}{*}{ Hemiptera } & \multirow{2}{*}{ Veliidae } & Vellia sp. & $x$ & & & $x$ & & & & & \\
\hline & & Trochophus sp. & $x$ & $x$ & & $x$ & $x$ & $x$ & & $x$ & \\
\hline & Mesoveliidae & Mesovellia sp. & $x$ & $x$ & $x$ & $x$ & $x$ & $x$ & $x$ & $x$ & \\
\hline & \multirow{2}{*}{ Corixidae } & Corixa sp. & $x$ & & & $x$ & $x$ & $x$ & $x$ & $x$ & \\
\hline & & Micronecta sp. & $x$ & $x$ & $x$ & & $x$ & & $x$ & & $x$ \\
\hline & Notonectidae & Notonecta sp. & $x$ & & $x$ & & $x$ & & $x$ & $x$ & \\
\hline & Belostomatidae & Belostoma sp. & $x$ & $x$ & & & $x$ & & & & \\
\hline & Nepidae & Nepa sp. & $x$ & $x$ & $x$ & $x$ & $x$ & $x$ & & & \\
\hline \multirow{8}{*}{ Coleoptera } & Hydrometridae & Hydrometra sp. & $x$ & & $x$ & & & $x$ & $x$ & $x$ & $x$ \\
\hline & Gyrinidae & Gyrinus sp. & $x$ & $x$ & $x$ & $x$ & $x$ & $x$ & $x$ & $x$ & $x$ \\
\hline & \multirow{2}{*}{ Dysticidae } & Daetis sp. & $x$ & & & $x$ & & & & & \\
\hline & & Ilybius sp. & $x$ & $x$ & & $x$ & $x$ & $x$ & $x$ & $x$ & $x$ \\
\hline & \multirow{2}{*}{ Elmidae } & Elmis sp. & $x$ & $x$ & $x$ & & $x$ & $x$ & $x$ & $x$ & $x$ \\
\hline & & Limnius sp. & $x$ & $x$ & & $x$ & $x$ & & $x$ & $x$ & \\
\hline & Hydrophilidae & Enochrus sp. & $x$ & $x$ & & & $x$ & $x$ & $x$ & $x$ & \\
\hline & Gomphidae & Gomphus sp. & $x$ & & $x$ & $x$ & & & & & $x$ \\
\hline \multirow{3}{*}{ Odonata } & Cordulegasteridae & Cordulegaster sp. & & $x$ & $x$ & $x$ & & & & & \\
\hline & Platycnemedidae & Platycnemis sp. & & & & $x$ & & & & & $x$ \\
\hline & Lestidae & Lestia sp. & $x$ & $x$ & & & $x$ & $x$ & $x$ & & \\
\hline \multirow{3}{*}{ Plecoptera } & Nemouridae & Nemoura sp. & $x$ & $x$ & & & $x$ & $x$ & $x$ & $x$ & \\
\hline & Chloroperlidae & Chloroperla sp. & $x$ & $x$ & & & $x$ & $x$ & $x$ & $x$ & \\
\hline & Chironomidae & Chironomus sp. & $x$ & & $x$ & $x$ & $x$ & & & $x$ & $x$ \\
\hline \multirow{3}{*}{ Diptera } & Tabanidae & Tabanus sp. & & $x$ & $x$ & $x$ & & & & & \\
\hline & Culicidae & Culicida sp. & & & & & & & & & $x$ \\
\hline & Anthomyiidae & Limnophora sp. & & & & & & & $x$ & & $x$ \\
\hline \multirow{3}{*}{ Oligochaeta } & Lumbriculidae & Lumbricus sp. & & & $x$ & & & & & & $x$ \\
\hline & Tubificidae & Tubifex sp. & & & & & & & & & $x$ \\
\hline & Erpobdellidae & Erpobdella sp. & & & $x$ & & & & $x$ & & $x$ \\
\hline \multirow{3}{*}{ Pulmonata } & Planobiidae & Planorbis sp. & $x$ & $x$ & & & $x$ & $x$ & $x$ & $x$ & \\
\hline & Sphaeriidae & Sphaerium sp. & $x$ & $x$ & & & $x$ & $x$ & & $x$ & \\
\hline & Psychomyiidae & Tinodos sp. & $x$ & & & & $x$ & & & & \\
\hline \multirow[t]{3}{*}{ Trichoptera } & Hydroptilidae & Hydroptilla sp. & $x$ & & & & $x$ & & $x$ & & \\
\hline & Hydropsychidae & Hydropsyche sp. & $x$ & & & & $x$ & & $x$ & & \\
\hline & Hydrobiidae & Potamopyrgus sp. & $x$ & $x$ & & & $x$ & $x$ & $x$ & $x$ & \\
\hline \multirow[t]{2}{*}{ Prosobranchiata } & Valvatidae & Valvata sp. & $x$ & $x$ & & & $x$ & $x$ & $x$ & $x$ & \\
\hline & Viviparidae & Viviparus sp. & $x$ & $x$ & & & $x$ & & $x$ & & \\
\hline \multirow{2}{*}{ Isopoda } & Gammaridae & Gammarus sp. & $x$ & $x$ & & $x$ & $x$ & $x$ & $x$ & & \\
\hline & Assellidae & Asellus sp. & $x$ & $x$ & & & $x$ & $x$ & $x$ & & \\
\hline Total & 38 & 44 & 35 & 26 & 15 & 18 & 32 & 23 & 28 & 22 & 15 \\
\hline
\end{tabular}

Total phosphorus (TP) levels were highest in station $\mathrm{R} / \mathrm{F}(0.83 \pm 0.12 \mathrm{mg} / \mathrm{L})$ followed by station OG3 with $0.762 \pm 0.1 \mathrm{mg} / \mathrm{L}$, while station $\mathrm{S} 1 \mathrm{had}$ the lowest concentration of $0.119 \pm 0.15 \mathrm{mg} / \mathrm{L}$ (Figure 6). Significant difference was observed between the sampling stations $(F=11.87, p=0.000)$ but the difference between 


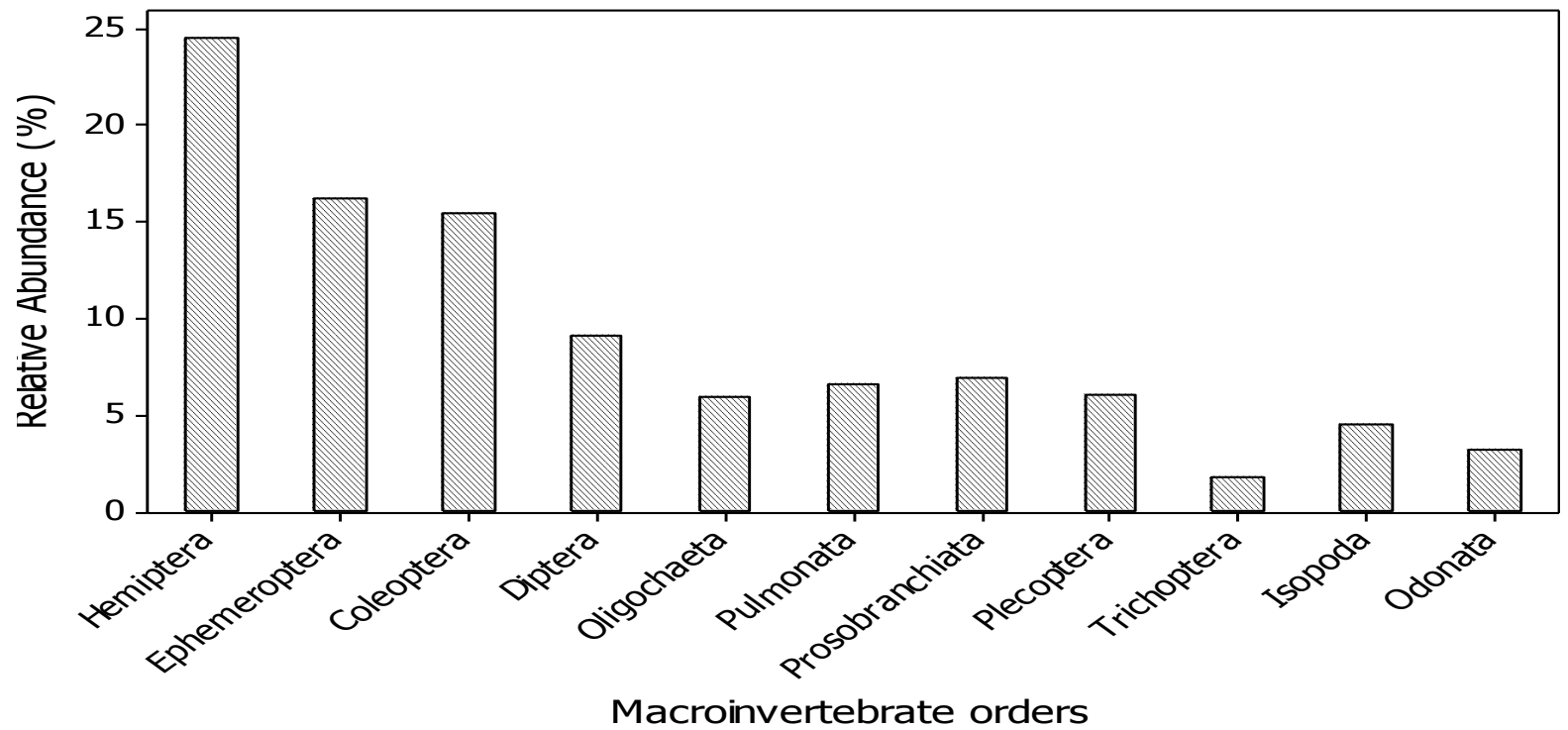

Figure 3. Bar graph showing relative abundance of the macroinvertebrate orders sampled in Nyando wetlands during the study period.

Table 4. Macroinvertebrate community attributes values (mean \pm SE) in Nyando wetland during the study period.

\begin{tabular}{|c|c|c|c|c|c|c|c|c|c|}
\hline \multirow{2}{*}{ Attribute } & \multicolumn{9}{|c|}{ Sampling station } \\
\hline & S1 & S2 & S3 & $R / F$ & W1 & W2 & OG1 & OG2 & OG3 \\
\hline D. I (H') & $2.47 \pm 0.05$ & $2.28 \pm 0.1$ & $1.49 \pm 0.02$ & $1.6 \pm 0.11$ & $2.37 \pm 0.13$ & $2.11 \pm 0.07$ & $2.19 \pm 0.1$ & $2.0 \pm 0.04$ & $1.54 \pm 0.1$ \\
\hline R. I 1/Ds & $8.93 \pm 1.9$ & $8.36 \pm 1.7$ & $3.65 \pm 0.4$ & $3.9 \pm 0.7$ & $8.72 \pm 1.4$ & $6.1 \pm 1.3$ & $8.15 \pm 1.8$ & $5.8 \pm 0.6$ & $3.7 \pm 0.5$ \\
\hline Evenness & $0.36 \pm 0.02$ & $0.34 \pm 0.04$ & $0.22 \pm 0.04$ & $0.28 \pm 0.03$ & $0.30 \pm 0.01$ & $0.21 \pm 0.03$ & $0.31 \pm 0.05$ & $0.23 \pm 0.02$ & $0.2 \pm 0.03$ \\
\hline Total A & 644 & 483 & 329 & 280 & 421 & 357 & 434 & 336 & 224 \\
\hline R.A (\%) & 18.2 & 13.6 & 9.2 & 10.2 & 11.9 & 6.9 & 12.3 & 9.6 & 6.2 \\
\hline \% ЕРТ & 29.3 & 22.8 & 6.7 & 15.3 & 25.8 & 26.1 & 20.9 & 21.8 & 5.1 \\
\hline \% Diptera & 5.9 & 6.2 & 31 & 9.8 & 6 & 7.3 & 10.4 & 7.7 & 37 \\
\hline EPT:Diptera & 4.7 & 3.7 & 0.22 & 1.8 & 4.3 & 3.8 & 2 & 2.8 & 0.14 \\
\hline$\%$ Tolerant & 5.9 & 6.2 & 48 & 9.8 & 6 & 7.3 & 12.2 & 11.6 & 49.2 \\
\hline Genera & 35 & 26 & 15 & 18 & 32 & 23 & 28 & 22 & 15 \\
\hline
\end{tabular}

R.I- Richness index; D.I- Shanon-weiner diversity index; EPT- total of individuals from orders Ephemeroptera, Plecoptera and Trichoptera; Total A- total abundance; R.A- relative abundance; SE-standard error of the mean.

occasions was insignificant $(F=3.59, p=0.052)$. The concentration of total nitrogen was highest at station $\mathrm{R} / \mathrm{F}$ $(0.224 \pm 0.05 \mathrm{mg} / \mathrm{L})$ and least at station S1 $(0.084 \pm$ $0.002 \mathrm{mg} / \mathrm{L}$ ) (Figure 6). Repeated measures of ANOVA revealed significant difference between sampling stations $(F=11.69, p=0.000)$ but the difference between sampling occasions was not significant $(F=14.57, p=0.075)$.

\section{Relationships between physico-chemical parameters, abundance and diversity}

Spearman's correlations analysis was done to determine the relationships between the physico-chemical parameters and macroinvertebrates. Abundance of sensitive macroinvertebrate taxa such as the EPT group was negatively correlated with all physico-chemical parameters considered except $\mathrm{DO}$ ( $\mathrm{mg} / \mathrm{L})$ and $\mathrm{pH}$ (Table 5). Taxon richness was negatively related with water temperature $(r=-0.475)$, conductivity $(r=-0.219)$, and nutrient levels $(r=-0.573)$, while it was positively related with $D O \mathrm{mg} / \mathrm{L}(\mathrm{r}=+0.521)$.

Considering individual macroinvertebrate taxa, the order Ephemeroptera showed a strong negative relationship with total nitrogen $(r=-0.673)$ and total phosphorus $(r$ $=-0.731$ ), while showing a strong positive relationship with $\mathrm{DO} \mathrm{mg} / \mathrm{L}(r=+0.656)$. Plecoptera also showed a strong negative correlation with TN $(-0.641)$ and TP $(r=-$ 0.757). There was a strong positive correlation between the order Diptera with temperature $(r=+0.519)$, TP $(r=$ $+0.662)$ and TN $(r=+0.510)$. Oligochaetes on the other 


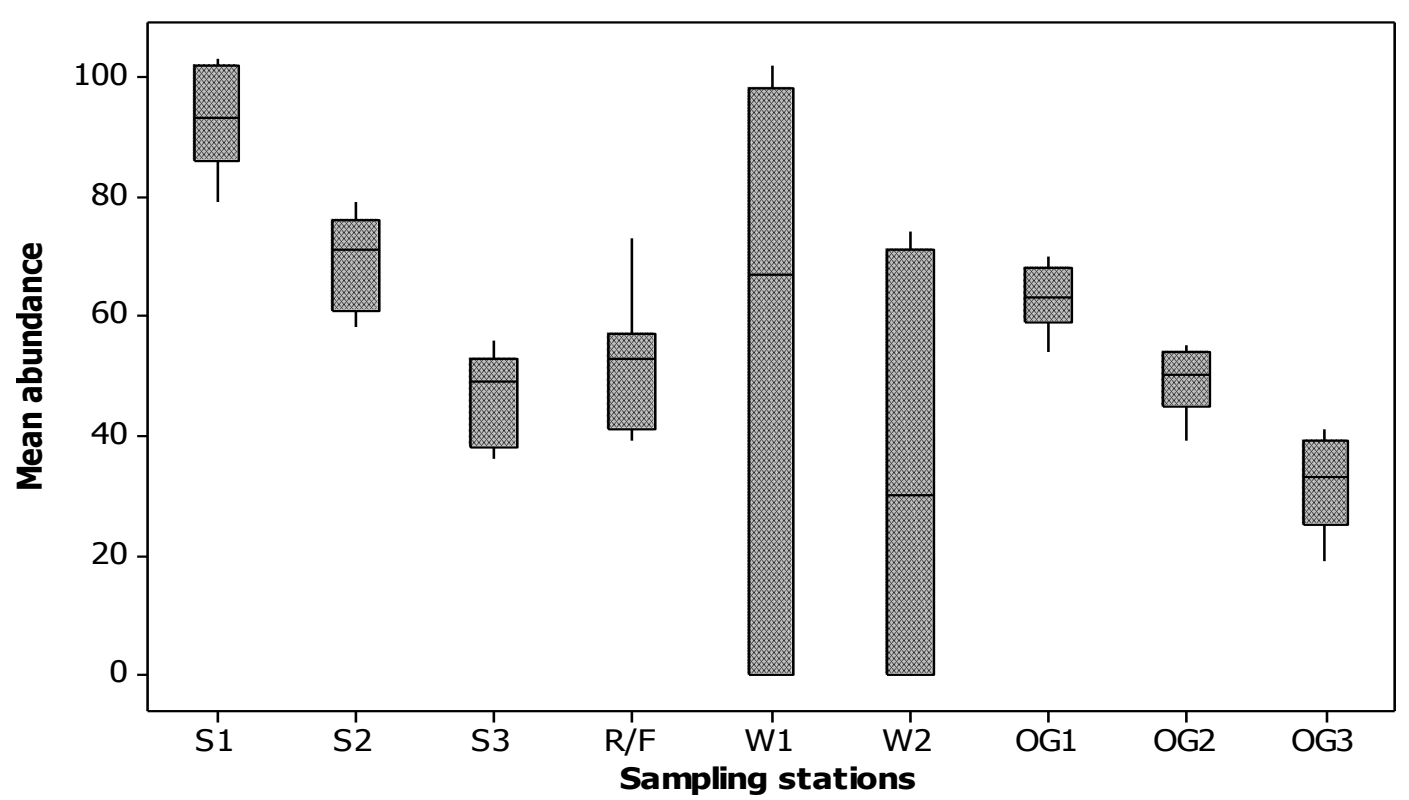

Figure 4. Box plot of macroinvertebrate mean abundance at the sampled stations in Nyando wetland during the study period.
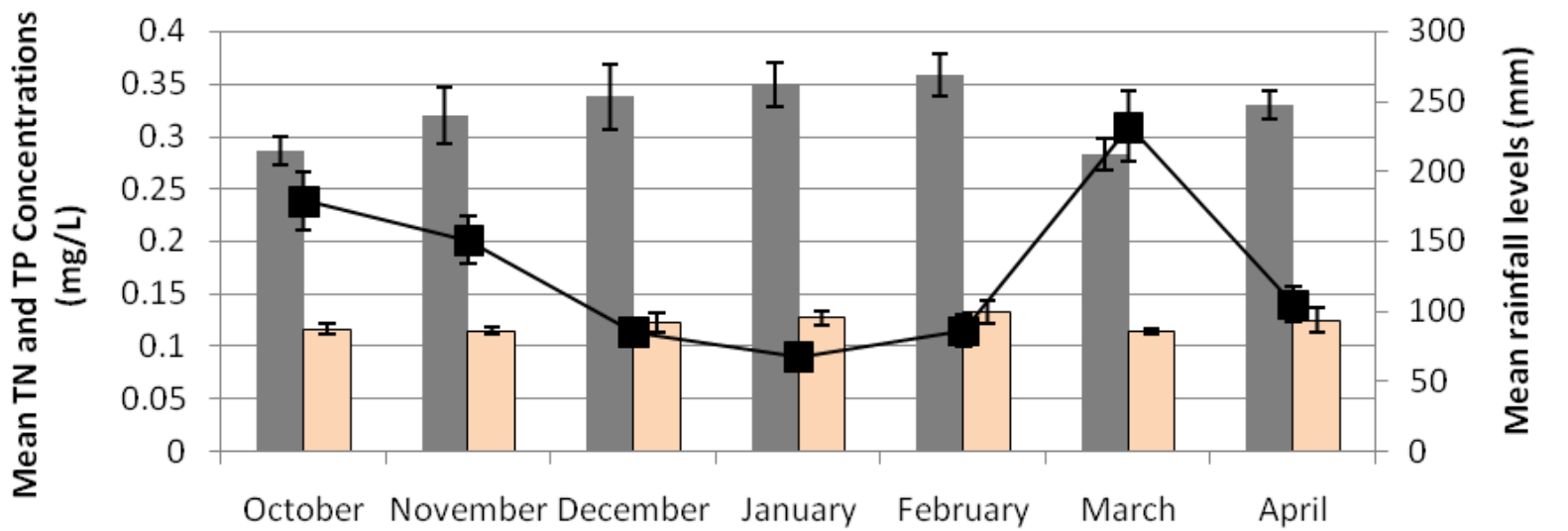

Sampling months

Figure 5. Bar graphs showing mean concentrations $\pm S E$ of $T P, T N$ and rainfall levels in Nyando wetlands during the study period.

hand a strong negative correlation with D.O $(r=-0.579)$, and $\mathrm{pH}(\mathrm{r}=-0.517)$ but had a strong positive correlation with temperature $(r=+0.647)$, TP $(r=+0.758)$ and TN $(r$ $=+0.574)$.

Macroinvertebrate abundance in Nyando wetlands was also affected by the water depth. During the study period, it was generally observed that abundance was lowest during the dry period of January and February when the water depth was lowest. The abundance was higher in October and November when the depth was relatively high. Water depth also affected other parameters like conductivity,temperature, TN and TP which increased with a decrease in water depth. The dissolved oxygen (DO $\mathrm{mg} / \mathrm{l}$ ) levels however decreased with a decrease in water depth.

\section{Macroinvertebrate index of biotic integrity (M-IBI)}

Out of the twenty macro invertebrate metrics selected, 


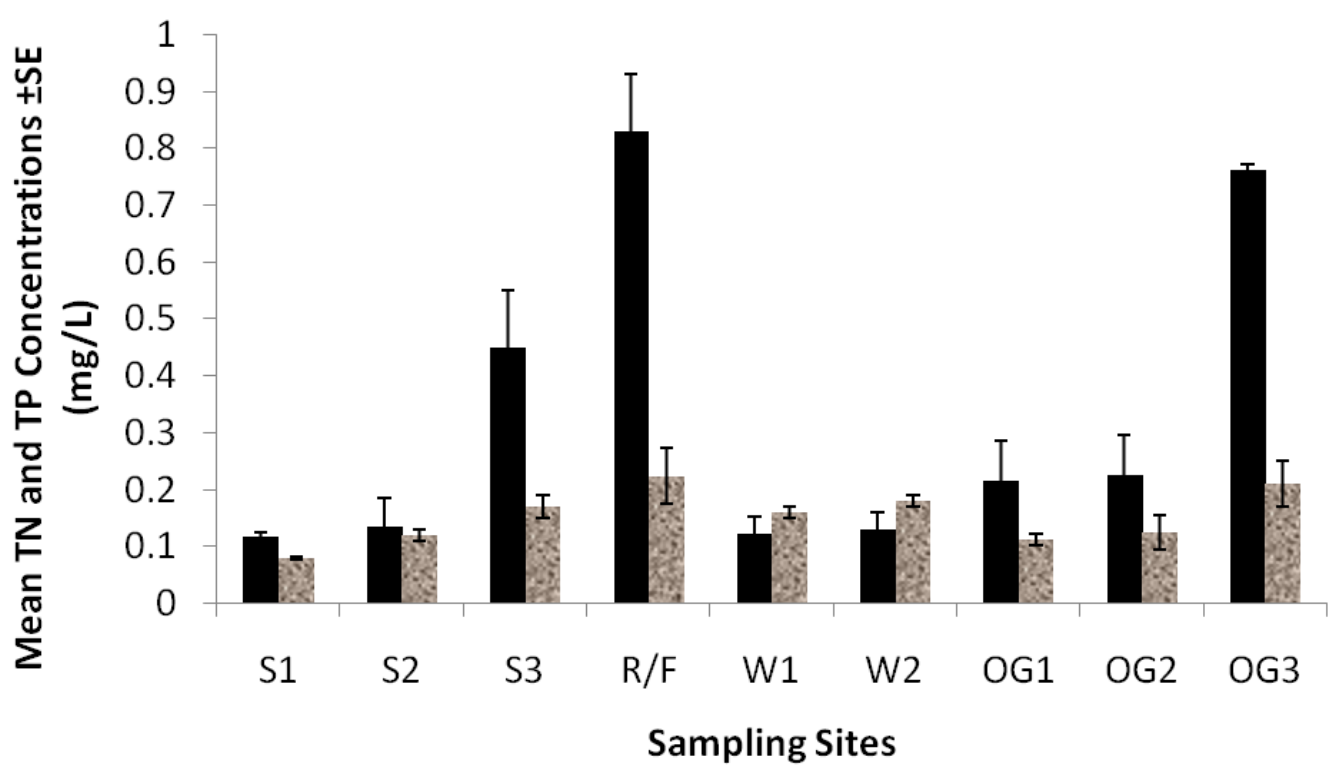

TP 娄 TN

Figure 6. Mean concentrations \pm SE of TP and TN per sampling station in Nyando wetland during the study period.

Table 5. Correlation coefficient ( $r$ ) between macro-invertebrate abundance and the water quality parameters in sampled stations in Nyando wetland.

\begin{tabular}{lcccccc}
\hline Taxa & \multicolumn{7}{c}{ Physico-chemical parameter } \\
\hline Order & $\mathbf{D . O} \mathbf{~ m g / L}$ & $\begin{array}{c}\text { Conductivity } \\
(\boldsymbol{\mu} \mathbf{S} / \mathbf{c m})\end{array}$ & $\begin{array}{c}\text { Temperature } \\
\left({ }^{\circ} \mathbf{C}\right)\end{array}$ & $\mathbf{p H}$ & $\begin{array}{c}\text { Total phosphorus } \\
(\mathbf{m g} / \mathbf{L})\end{array}$ & $\begin{array}{c}\text { Total nitrogen } \\
(\mathbf{m g} / \mathbf{L})\end{array}$ \\
\hline Ephemeroptera & $+0.656^{*}$ & -0.336 & -0.461 & +0.244 & $-0.731^{*}$ & $-0.673^{*}$ \\
Plecoptera & +0.331 & -0.044 & -0.394 & +0.159 & $-0.757^{*}$ & $-0.641^{*}$ \\
Trichoptera & 0.139 & -0.366 & -0.270 & +0.130 & -0.317 & -0.441 \\
Diptera & -0.463 & +0.276 & $+0.519^{*}$ & -0.347 & $+0.662^{*}$ & $+0.510^{*}$ \\
Oligochaetes & $-0.579^{*}$ & +0.137 & $+0.647^{*}$ & $-0.517^{*}$ & $+0.758^{*}$ & $+0.574^{*}$ \\
Hemiptera & $+0.518^{*}$ & +0.257 & -0.119 & +0.183 & -0.344 & -0.244 \\
Coleoptera & +0.217 & +0.153 & -0.264 & -0.063 & -0.417 & -0.217 \\
Pulmonata & +0.241 & +0.194 & -0.048 & +0.037 & $-0.550^{*}$ & -0.433 \\
Prosobranchiata & -0.285 & +0.326 & +0.374 & -0.129 & +0.228 & +0.447 \\
Odonata & -0.067 & -0.321 & +0.043 & +0.169 & +0.350 & +0.261 \\
Isopoda & +0.125 & -0.093 & -0.382 & +0.153 & -0.356 & -0.310 \\
\hline
\end{tabular}

*Indicates strong relationships.

fifteen were found relevant to Nyando wetland and were subjected to Mann-Witney $U$ test. Only ten metrics out of the fifteen met the test criteria and were used for the development of $\mathrm{IBI}$ for the wetland. The metrics include total number of genera, number of genera from order Ephemeroptera, \% EPT, \% Diptera, EPT: Diptera, \% oligochaetes, Shonon-weiner diversity index, \% tolerant taxa, \% predators and \% filterers.

The reference station (S1) and the other stations showed differences in the final IBI developed using macroinvertebrate taxa assemblages (Table 6). Station S2 had the highest score of 46 thus categorized as excellent followed by station W1 which had a total score of 44 and was categorized as good. Stations S3 and OG3 recorded the least scores of 12 and were in the category of very poor whereas station R/F had a score of 18 and categorized as a poor station. Stations OG1 and OG2 had total IBI scores of 28 each falling into the ecological 
Table 6. Metrics used stations, individual scores and the overall IBI score.

\begin{tabular}{lcccccccccccc}
\hline \multirow{2}{*}{ Metric } & \multicolumn{1}{c}{ Station } & \multicolumn{4}{c}{ Scoring criteria } \\
\cline { 2 - 14 } & S1 & S2 & S3 & R/F & W1 & W2 & OG1 & OG2 & OG3 & $\mathbf{5}$ & $\mathbf{3}$ & $\mathbf{1}$ \\
\hline Total no of genera & 5 & 5 & 1 & 3 & 3 & 3 & 5 & 3 & 1 & $35-25$ & $24-16$ & $<16$ \\
Ephemeroptera taxa & 5 & 3 & 1 & 1 & 5 & 3 & 3 & 3 & 1 & $7-5$ & $4-2$ & $<2$ \\
\%EPT & 5 & 5 & 1 & 3 & 5 & 5 & 3 & 3 & 1 & $30-22.5$ & $22.5-15$ & $<15$ \\
\%Diptera & 5 & 5 & 1 & 3 & 5 & 5 & 1 & 3 & 1 & $<7.4$ & $7.4-8.9$ & $>8.9$ \\
EPT : Diptera ratio & 5 & 5 & 1 & 1 & 5 & 5 & 1 & 3 & 1 & $4.7-3.5$ & $3.5-2.4$ & $<2.4$ \\
\% Oligochaetes & 5 & 3 & 1 & 1 & 3 & 1 & 1 & 1 & 1 & $<1.0$ & $1.0-1.2$ & $>1.2$ \\
S. diversity Index & 5 & 5 & 3 & 3 & 5 & 5 & 5 & 5 & 3 & $2.5-1.9$ & $1.9-1.24$ & $<1.24$ \\
\% Tolerant individuals & 5 & 5 & 1 & 1 & 5 & 5 & 1 & 1 & 1 & $<8.4$ & $8.4-10.1$ & $>10.1$ \\
\% Predators & 5 & 5 & 1 & 1 & 3 & 1 & 3 & 3 & 1 & $34-25$ & $25-17$ & $<17$ \\
\% Filterers & 5 & 5 & 1 & 1 & 5 & 3 & 5 & 3 & 1 & $<9.8$ & $9.8-11.7$ & $>11.7$ \\
Total IBI score & 50 & 46 & 12 & 18 & 44 & 36 & 28 & 28 & 12 & 50 & 30 & 10 \\
\hline
\end{tabular}

integrity class of fair.

\section{DISCUSSION}

\section{Macroinvertebrates diversity and abundance}

According to the results from this study, stations OG3 and S3 had 15 and 14 genera, while station S1 had a total of 33 genera. The low abundance and composition of macroinvertebrates in stations S3, OG3 and R/F could be attributed mainly to high human activities taking place just above the sites. The sites had cattle grazing, domestic washing, crop cultivation and daily fish landing, activities that have the potential to increase nutrient levels and sedimentation. At R/F the conversion from natural habitat and the frequent human disturbance could have been responsible for the low abundance. Nutrient input through urine and fecal deposition and trampling of sediments by humans and livestock which were the common occurrences in these disturbed stations could have direct impact on aquatic biota. Similar observations were made by Griffith et al. (2005) on his study of aquatic macroinvertebrates. Both increased nutrient levels and sedimentation which are elements of pollution have negative impacts on macroinvertebrate abundance since pollution inflows have been shown to reduce macro invertebrate abundance and diversity (Aura et al., 2010).

The difference in abundance between stations could also be attributed to the difference in vegetation cover which had an impact on temperature and nutrient levels. The low water temperature at stations S1, W1 and OG1 can be explained by higher vegetation cover, which provides the shade that moderates temperature. The Cyperus covered sites had lower temperatures and nutrient levels as compared to the open sites. Wetland vegetation are known to actively take up nutrients while their canopy shields direct sunlight (Wang and Lyons, 2003) hence the difference in abundance between stations OG1 and OG2; sites that were relatively closer and shared most site characteristics except for the degree of openness. Station OG1 had much macrophyte cover as compared to station OG2 which could be due to water levels that discouraged grazing much further from the beach.

Diptera, oligochaeta and odonata dominated stations S3, OG3 and R/F which could be attributed to high nutrient levels and low DO levels recorded at these sites that could have been caused by discharges due to raw crop cultivation, cattle grazing and domestic washing. Dipterans and oligochaetes have been found to withstand high nutrient concentrations and low DO levels probably because these animals have glycogen content and reduced activity which allows them to withstand increased conductivity levels (Welch, 1992). This is in line with then report of Margolis et al. (2001) who found that changes in the benthic macroinvertebrate assemblages are not only determined by changes in the type and availability of food but also with the differences in the ability of resident genera to tolerate the environment around it. Masese et al. (2009) found high abundance of dipterans in disturbed sites and attributed it to organic pollution caused by enrichment and sedimentation caused by agricultural activities and animal use of the riparian areas.

The total EPT group in the disturbed stations comprised only $5.1 \%$ in OG3 and $6.7 \%$ in S3 which probably emphasizes their limited chances of survival in such areas. The EPT groups are sensitive to disturbance and decrease with an increase in nutrient levels (Mason, 2002). The relative abundance of the intolerant group in all sites was believed to be influenced by organic matter and availability of food for consumption that may be triggered by nutrient enrichment. This concurs with Aura et al. (2010) and Mason (2002), who found similar results and attributed it to the influence of organic matter and food availability on the abundance and distribution of aquatic macroinvertebrate taxa.

There was a general decline in abundance of intolerant taxa as the wetland moved off-shore where disturbance 
was evidently higher. The higher disturbance could be responsible for an increase in conductivity and nutrient levels and a decline in DO levels. High conductivity and nutrient levels coupled with low DO levels affects the occurrence and abundance of intolerant macro invertebrate taxa (Hawkers, 1979).

Pollution tolerant species like Chironomus sp., Tubifex sp., Lumbricus sp., Sphaerium sp. and Erpobdella sp. were more abundant in the disturbed station which could conform to the physical structure that could have provoked perturbations of invertebrate communities, but the response to such events vary according to species. Kari and Rauno (1993) concluded that the distribution of aquatic macroinvertebrate occurrence is set by physical and chemical tolerance of the individual macro invertebrates to certain environmental factors. A lower index is a sign of disturbance over time, where a few tolerant genera dominate the community while higher values are recorded from relatively undisturbed areas. Due to this fact, stations which had lower diversity index values received a lower score and vice versa. Shannon-Wiener diversity index $\left(\mathrm{H}^{\top}\right)$ usually have values ranging between 1.5 and 3.5, rarely rising above 4.5 (Magurran, 1988).

Station $\mathrm{S} 1$ had the highest diversity index of $2.47 \pm$ 0.05 whereas station S3 had the lowest $\left(H^{\prime}=1.49 \pm 0.1\right)$. Variations in diversity obtained could be as a result of moderately high conductivity values and DO levels that were significantly different between the sampling stations within the wetland. Increased conductivity has an influence on osmoregulation of the aquatic invertebrates leading to sensitive freshwater organisms either to disappear or adapt (Spiels and Mitch, 2000). The low diversity in Station $\mathrm{S} 3\left(\mathrm{H}^{\prime}=1.49 \pm 0.1\right)$ was probably due to few microhabitats observed in the area coupled with an open access for livestock invasion that leads to herbivory of aquatic vegetation and nutrient input via urine and fecal deposition and trampling of sediments which have direct impact on aquatic ecosystems, as also observed by Griffith et al. (2005).

The highest taxon richness of 33 genera recorded in S1 could not only be due to several microhabitats that may have favoured availability of more niches for macro invertebrates existence but mainly the absence of frequent and major human activities that could cause hydrological perturbations to such areas. This concurs with Matthaei et al. (2000), who showed that the distribution of benthic macroinvertebrates in aquatic systems is dynamic and is strongly influenced by the hydrological disturbance regime. It was therefore realized in this study that diversity is a function of seasonal differences, and human disturbance which influences the availability of organic matter as also supported by Mason (2002).

\section{Macroinvertebrate diversity and abundance versus nutrients}

Variations recorded in the nutrient concentrations among the stations, could possibly be due to the difference in the magnitude of activities like crop cultivation, animal grazing and domestic washing that all have an effect on the concentration of nutrients. Robert and Rankin (1998) obtained similar results in a low order stream of $>0.61$ $\mathrm{mg} / \mathrm{L}$ for $\mathrm{TN}$ at a site that anthropogenic impact seemed to be more. Nutrients availability in an aquatic environment is primarily influenced by several factors which include application of fertilizers (Carpenter et al., 1998). In Nyando wetland, application of fertilizers was evident in OG3 and S3, sites that recorded high nutrient levels. Total nitrogen (TN) and TP concentrations at the relatively undisturbed site $S 1$ recorded lowest levels than the rest of the stations probably due to absence of crop farming and the self-cleansing effect of the system. Similar results were also obtained by Carpenter et al. (1998) and Masese et al., (2009).

There were significant correlations of macro invertebrates abundance and diversity with TP and TN among the stations (Table 7). Stations with high macro invertebrate diversity recorded low levels of TN and TP. For example, the station at S1 that recorded the highest diversity value of $2.47 \pm 0.05$ had the lowest TP and TN concentrations of $0.119 \pm 0.05$ and $0.08 \pm 0.02 \mathrm{mg} / \mathrm{L}$, respectively. Station OG3 that recorded a higher TP $(0.76$ $\pm 0.1 \mathrm{mg} / \mathrm{L})$ and TN $(0.21 \pm 0.04 \mathrm{mg} / \mathrm{L})$ concentrations, had a lower diversity $(\mathrm{H}=1.54 \pm 0.1)$. An overall weak negative correlation value $(r=-0.23, r=-0.29)$ between macro invertebrates Shannon-Weiner diversity with TP and TN was registered in this study, indicative of a negative relationship between macroinvertebrate abundance and diversity and nutrient levels. In a similar study, Griffith et al. (2005) obtained a negative value $(r=-$ 0.309 ) that showed a negative correlation of macro invertebrate diversity with increased nutrient levels though they noted high TN and TP flow into the Southern Montana wetlands. This could imply that high nutrient levels which are a sign of disturbance have an impact on macroinvertebrates ecology and diversity. Harding et al. (1999) noted similar weak significant correlation results and suggested that high periphyton biomass due to nutrient enrichment and sedimentation in some of the stations that they sampled favoured chironomids, snails and oligochaetes at the expense of ephemeroptera and trichoptera. The authors noted a decline in diversity of macro invertebrates, with the low abundance or absence of ephemeroptera and trichoptera downstream due to increased nutrient levels because of agricultural activities and urbanization. A weak positive correlation between nutrient levels and tolerant taxa was also observed in this study $(r=+0.31)$. There was high abundance of chironomids and oligochaetes in disturbed stations S3 and OG3. This finding concurs with that of Harding et al. (1999) who found the highest macroinvertebrate abundance of tolerant species such as Chironomus sp. in areas of increased nutrient levels. Griffith et al. (2005) noted that changes in the structure of the microbial com- 
Table 7. Table showing physico-chemical parameter values (minimum - maximum) at different sampling stations in Nyando wetland during the study period.

\begin{tabular}{|c|c|c|c|c|c|c|c|c|c|}
\hline \multirow{2}{*}{ Parameter } & \multicolumn{9}{|c|}{ Sampling station } \\
\hline & S1 & S2 & S3 & W3 & W1 & W2 & OG1 & OG2 & OG3 \\
\hline E.C $(\mu \mathrm{S} / \mathrm{cm})$ & $506-579$ & $498-573$ & $515-585$ & $323-408$ & $189-253$ & $203-269$ & $226-319$ & $210-298$ & $242-341$ \\
\hline DO (mg/l) & $0.42-0.72$ & $0.69-0.85$ & $0.23-0.29$ & $0.84-1.68$ & $0.24-0.36$ & $0.13-0.28$ & $0.35-0.61$ & $0.39-0.68$ & $0.11-0.22$ \\
\hline Temp $\left({ }^{\circ} \mathrm{C}\right)$ & $19.8-21.1$ & $21.4-23.2$ & $20.1-22.4$ & $28.1-30.2$ & $20.9-22.1$ & $21.7-23.4$ & $20.3-22.1$ & $24.1-26.7$ & $22.9-25.6$ \\
\hline $\mathrm{pH}$ & $5.78-6.18$ & $5.74-6.09$ & $5.69-5.98$ & $6.52-7.21$ & $5.68-6.05$ & $7.19-7.68$ & $5.29-5.47$ & $5.92-6.44$ & $5.75-6.21$ \\
\hline $\mathrm{TP}$ (mg/l) & $0.113-0.125$ & $0.125-0.142$ & $0.32-0.53$ & $0.72-0.92$ & $0.115-0.127$ & $0.12-0.138$ & $0.174-0.241$ & $0.196-0.247$ & $0.66-0.82$ \\
\hline TN (mg/l) & $0.06-0.11$ & $0.09-0.16$ & $0.13-0.21$ & $0.179-0.249$ & $0.11-0.18$ & $0.15-0.22$ & $0.09-0.118$ & $0.1-0.178$ & $0.17-0.26$ \\
\hline Depth (m) & $0.58-2.37$ & $0.45-1.66$ & $0.24-1.44$ & $0.35-0.78$ & $0.48-1.87$ & $0.29-1.64$ & $0.78-2.07$ & $0.54-1.71$ & $0.46-0.98$ \\
\hline
\end{tabular}

E.C- Electrical conductivity in $\mu \mathrm{S} / \mathrm{cm}$; DO- dissolved oxygen in $\mathrm{mg} / \mathrm{l}$; Temp- temperature $\left({ }^{\circ} \mathrm{C}\right) ; \mathrm{TP}$ - total phosphorus (mg/l); TN- total nitrogen (mg/l); Depth- mean water depth (m).

ponents did not significantly affect the macro invertebrate community (where only a few taxa showed changes because of the nutrient addition) or the overall stream metabolism. Herrmann (1999) noted that slight eutrophication seems to favour increased diversity, however, excess amounts of nutrients resulting in increased primary production and consequently oxygen depletion, probably affecting macroinvertebrate diversity negatively.

\section{Macroinvertebrate index of biotic integrity}

Bioindicators, like macroinvertebrates are organisms whose presence, absence or condition provides information on aquatic ecosystem quality (Mason, 2002). The approximation or deviation of the macroinvertebrates occurrence to the reference station is a sign of particular environmental characteristics of anthropogenic impact. The biological information contained in the macroinvertebrate index of biotic integrity (IBI) of this study and its component metrics has a potential of passing the conservation and restoration efforts needed for the entire Nyando wetland. Karl et al. (2003) used the metrics of EPT genera, percent mayflies, percent chironomids, percentage of other dipterans and other insects and the abundance of macroinvertebrates in relation to the same characteristics in the reference stations. A few similar metrics were used in this study such as percentage intolerant (EPT), percentage tolerant, abundance of macroinvertebrates and abundance of pollution tolerant oligochaetes and chironomids. Both studies signified the deleterious effect of nutrient enrichment into aquatic ecosystem. This also compares with the studies done on other systems (Roy et al., 2001; Taylor and Francis, 2005) to come up with metrics and an IBI for evaluating the biotic integrity using macroinvertebrate communities. The IBI has also shown a similarity with those IBI scores that have successfully correlated with human activities like urbanization and agriculture (Carpenter et al., 1998; Griffith et al., 2005), and riparian destruction (Cragg, 1961; Griffith et al., 2005). This is an indication that the index could probably be a preliminary estimate of the current biotic integrity of all the stations and for the entire wetland.

Metric variability and response of metrics to impaired sites indicated that this IBI responded to the range of biological conditions found in the ecoregion. For example, according to the calculated IBI (Table 5), station S3 and OG3 realized
12 points while station S2 obtained 46 points out of the total 50 points. Based on the integrity classes, station S2 was within the first category of excellent habitat quality. Station S3 and OG3 were under the fifth category of very poor habitat quality. The difference in water quality between stations S2, S3 and OG3 could be partly attributed to the intense human activities like agricultural farms just above the sampling sites. Station W1 recorded good habitat quality probably due to the increased water volume that was observed in the area during the rainy season. Another reason could be the dense vegetation which to some extent buffers any runoffs into the wetland water and regulates extreme temperatures. Station W2 recorded good habitat quality. This may be probably because of organic farming and dense bank vegetation that offered many micro-habitats for macroinvertebrates and minimized nutrient influx from the rice fields adjacent to it. The calculated IBI depicts that Singida transect within Nyando wetland is of good quality where as the Ogenya transect within the same wetland is of fair to poor quality. Ogello (2005), in his study of small water bodies within the Lake Victoria catchment realized 30 points for a high altitude area while the low altitude region obtained 17 points out of a total of 
50 points, but each metric in his case had a maximum score of 10 and not 5 as used here. Aura et al. (2010) using a maximum score of 5 for each metric as used in this study realized 39 points for the less disturbed sites while for the disturbed site he obtained 19 points.

For management, the metrics are indicative of a changing environment under the influence of intermediate levels of degradation. With increasing human population on the catchment area, the situation is likely to be exacerbated. Therefore, the challenge is to halt the current trend and improve the habitat integrity at the stations. However, as observed by Omukoto (2007), development of IBI for tropical ecosystems faces the setback of inadequate reference information to construct indices. This $\mathrm{M}-\mathrm{IBI}$ developed from this study provides the first attempt to use the methodology in Nyando wetland. However, further studies need to be carried out on the ecology of the wetland to help in the fine tuning of the responses observed in this study.

\section{Conclusions}

Disturbed sites recorded lower taxa richness as compared to the relatively undisturbed sites. The abundance of macroinvertebrates was higher during the period of rains and reduced significantly during the dry period. The Wasare transect showed the highest variation in terms of macroinvertebrate abundance and diversity probably due to the fast changes in water depth.

There were significant differences both in spatial and temporal distribution of functional feeding groups in Nyando wetland. Among the functional groups encountered, predators and collector-gatherers dominated all the sampling stations during the entire period of the study due to availability of organic matter in the wetland. The null hypothesis which stated that there is no variation in the composition and abundance of macroinvertebrate functional feeding groups between sampling sites and occasions was therefore rejected.

The EPT group as confirmed in this study inhabit good quality areas except for certain genera in the order ephemeroptera that were found throughout the wetland while the tolerant taxa such as oligochaeta, odonata and diptera dominate areas of poor quality. The diversity and abundance of macroinvertebrates significantly correlated with the TP and TN levels. This indicates that macro invertebrates abundance and diversity and nutrient levels correlated in this wetland thus the null hypothesis that there is no relationship between the nutrient levels and the diversity and abundance of macro invertebrate community is therefore rejected.

Macroinvertebrates found along Nyando wetland responded to disturbance which made it possible to develop an index for use in monitoring the wetland. Metrics considered exhibited variable conditions between sites which was a verification of their use in various bio monitoring programs and resulted in the rejection of the null hypothesis that the response of macro invertebrate within Nyando wetland is not sufficient enough to be used for biomonitoring.

\section{REFERENCES}

APHA (American Public Health Association) (1998). Standard methods for the examination of water and wastewater, $20^{\text {th }}$ edn. Washington, D.C.

Aura CM, Raburu PO, Herrmann J (2010). A Preliminary Macroinvertebrate IBI for biossesment of the Kipkaren and Sosiani Rivers, Nzoia River Basin, Kenya. Lakes and Reservoirs 15 (2):119128.

(Global Environmental Facility) (2007). Western Kenya Integrated Ecosystem. Project Executive Summary. $<$ http://www.gefweb>.org/Documents/Council-Documents/C23/MFA-Kenya-Executive summary/

Griffith MB, Hill B, McCormick H, Kaufmann R, Herlihy T, Selle AR (2005). Comparative application of indices of biotic integrity based on periphyton, macroinvertebrates, and fish to southern Rocky Mountain streams. Ecol. Indic. 5: 117- 136.

Karr JR, Chu EW (1981). Biological Monitoring and Assessment: Using Multimetric Indices Effectively. EPA 235- R97-001. University of Washington, Seattle, WA. pp. 21.

Masese FO, Muchiri M, Raburu PO (2009). Macroinvertebrate assemblages as biological indicators of water quality in the Moiben River, Kenya. Afr. J. Aquat. Sci. 34:15-26.

Mason CF (2002). Biology of freshwater pollution. $4^{\text {th }}$ Ed. Pearson Education Ltd. Essex. London. 38pp.

Matthaei CD, Arbuckle CJ and Townsend CR (2000). Stable surface as refugia for invertebrates during disturbance in a New Zealand stream. J. N. Am. Benthological Soc. 19: 82-93.

Merritt RW, Cummins KW (1996). An introduction to the Aquatic Insects of North America. $3^{\text {rd }}$ edn. Kendall / Hunt Publishing Company, Dubuque, IA. pp. 862.

Ogello OE (2005). The use of macroinvertebrate diversity to assess the quality of small water bodies within Lake Victoria Catchments, Kenya. Unpublished Bsc., (Fisheries) Dissertation.

Omukoto JO (2007). Development of a Fish Index of Biotic Integrity (IBI) for Satellite Lakes within Yala Swamp, Lake Victoria Basin, Kenya. M.Phil.thesis,Moi University, Kenya.

Quigley M (1977). Invertebrates of streams and Rivers: a key to identification. Edward Arnold Ltd. London. pp.84.

Raburu PO, Masese FO, Mulanda CA (2009). Macroinvertebrate Index of Biotic Integrity (M-IBI) for monitoring rivers in the upper catchment of Lake Victoria Basin, Kenya. Aquat. Ecosyst. Health Manage. 12: 197-205.

Roy AH, Rosemond DA, Leigh DS, Paul MJ, Wallace JB (2001). Efforts of changing land use on macroinvertebrate integrity. Georgia Water Resource Conference. University of Georgia, Athens, G.A. pp. 47.

Spiels DJ, Mitsch WJ (2000). Macroinvertebrate Community Structure in High and Low-Nutrient Constructed Wetlands. J. Society Wetland Sci. 20: 716-729

UNEP (2006). Lake Victoria basin environmental outlook: environment and development. UNEP, Nairobi. 